\title{
PARÂMETROS DE QUALIDADE DO LEITE CRU FORNECIDO PARA INDÚSTRIA DE PROCESSAMENTO DE PRODUTOS LÁCTEOS
}

\author{
Franciele Ávila Garcia ${ }^{1}$, Vania Silva Carvalho ${ }^{1}$, Nayana Ribeiro Soares ${ }^{2}$, Suzane Martins Ferreira ${ }^{1}$ \\ ${ }^{1}$ Instituto Federal Goiano - Campus Morrinhos, GO. ${ }^{2}$ Instituto Federal do Pará Campus Rural de Marabá.
}

\section{RESUMO}

A qualidade do leite é definida por parâmetros de características físicas, químicas, sensoriais, baixa contagem bacteriana, ausência de microrganismos patogênicos, baixa contagem de células somáticas, ausência de conservantes químicos e de resíduos de antibióticos. Estes resíduos tratam -se de uma contaminação química no leite e representam riscos à saúde pública e prejuízos para a indústria de processamento de produtos lácteos, pois não há tratamento tecnológico que consiga inativá-los. Assim objetivou-se com este estudo avaliar a qualidade do leite cru utilizado em uma indústria de processamento de produtos lácteos da região sul do Estado de Goiás referente aos parâmetros de antibiótico, gordura, lactose, proteína, estrato seco total (EST), estrato seco desengordurado (ESD), contagem de células somáticas (CCS) e contagem bacteriana total (CBT) de quatro produtores no período de agosto a outubro de 2015. Foram avaliadas 55 amostras, onde 7,3\% destas apresentaram resíduos de antibióticos betalactâmicos detectados para o produtor A. As médias estatísticas em desacordo com os padrões estabelecidos pela Instrução Normativa no 62 foram percebidas para o produtor $A$ com $8,18 \%$ de ESD, $42,64 \times 10^{5} \mathrm{CS} / \mathrm{mL}$ de CCS e $13,26 \times 10^{5}$ $\mathrm{UFC} / \mathrm{mL}$ de CBT. A média geométrica de CCS dos produtores A e $\mathrm{C}$ também não atenderam a IN 62 com valores de $37,42 \times 10^{5} \mathrm{CS} / \mathrm{mL}$ e $6,69 \times 10^{5} \mathrm{CS} / \mathrm{mL}$ respectivamente. Observou-se que a alta CCS pode indicar a presença de infecções no animal e favorecem alterações físicas e químicas no leite que prejudica a qualidade do mesmo e consequentemente dos derivados lácteos.

Palavras-chave: legislação; CCS; antibiótico.

\section{MILK QUALITY PARAMETERS RAW PROVIDED FOR PROCESSING INDUSTRY DAIRY}

\begin{abstract}
Milk quality is defined by parameters of physical, chemical, sensory, low bacterial count, absence of pathogens, low somatic cell count, absence of chemical preservatives and antibiotic residues. These residues treat If a chemical contamination in milk and pose risks to public health and damage to the processing of dairy industry because there is no technological treatment that can inactivate them. So aim with this study was to evaluate the quality of the raw milk used in a dairy processing industry of Goiás state southern region related to antibiotic parameters, fat, lactose, protein, total dry layer (EST), dry layer degreased (ESD), somatic cell count (SCC) and total bacterial count (TBC) of four producers in the period from August to October 2015 were evaluated 55 samples, which showed $7.3 \%$ of residues of betalactam antibiotics detected for producer $A$. the average statistics at odds with the standards established by Instruction No. 62 were perceived to producer a with $8.18 \%$ of ESD, $42.64 \times 10^{5} \mathrm{CS} / \mathrm{mL}$ of CCS and $13.26 \times 10^{5} \mathrm{CFU} / \mathrm{mL} \mathrm{CBT}$. The geometric mean of CCS producers A and C also did not attend the IN 62 to values $37.42 \times 10^{5} \mathrm{CS}$ $/ \mathrm{mL}$ and $6.69 \times 10^{5} \mathrm{CS} / \mathrm{mL}$ respectively. It was observed that the SCC may indicate the presence of infection in animals and promote physical and chemical changes in the milk impairs its quality and consequently milk derivatives.
\end{abstract}

Keywords: legislation; SCC; antibiotic. 


\section{INTRODUÇÃO}

Do ponto de vista fisiológico, o leite pode ser definido como o produto da secreção das glândulas mamárias das fêmeas mamíferas, após o parto, com a finalidade de alimentar a prole na primeira fase de sua vida (SILVA, 2014). É um alimento de alto valor nutritivo, fonte de proteínas, carboidratos, lipídios, vitaminas e sais minerais. Contém em torno de $87,6 \%$ de água, $12,4 \%$ de sólidos totais, 4,52\% de lactose, 3,61\% de gordura e 3,28\% de proteína (ALMEIDA, 2013).

A qualidade do leite é definida por parâmetros de características físicas e químicas, organolépticas, baixa contagem bacteriana, ausência de microrganismos patogênicos, baixa contagem de células somáticas, ausência de conservantes químicos e de resíduos de antibióticos (ARAUJO et al., 2015).

Com isso, visando a garantia de um alimento seguro, o Ministério da Agricultura, Pecuária e Abastecimento (MAPA) reformulou a Instrução Normativa $n^{\circ} 51$ de setembro de 2002 , e publicou em dezembro de 2011 a Instrução Normativa n62 (IN 62). A IN 62 aprovou o Regulamento Técnico de Identidade e Qualidade do Leite Cru Refrigerado, em que foram estabelecidos os requisitos microbiológicos, físicos e químicos que o leite deve atender (BRASIL, 2011).

Dentre os requisitos estabelecidos pela legislação, a contaminação química por antibióticos no leite representa riscos à saúde pública e prejuízos para a indústria de processamento de produtos lácteos. Além disso, essas substâncias não são eliminadas no beneficiamento, podendo representar perigo até nos derivados fabricados com essa matéria-prima (NERO et al., 2007). De acordo com Araújo et al. (2015), a presença de resíduos de antibiótico é um fator de rejeição dentro da indústria uma vez que torna a matéria-prima inadequada para o seu uso, visto que não há tratamento tecnológico que consiga inativar tais substâncias. De todo modo, os riscos apresentados à saúde dos consumidores são representados pelas reações alérgicas, frequentemente relacionadas aos antibióticos betalactâmicos (penicilinas), podendo desencadear choque anafilático em indivíduos sensíveis (SILVA, 2009).

Segundo Silva et al. (2013), os resíduos de antibióticos no leite decorrem indiretamente em consequência do tratamento veterinário do gado leiteiro proveniente da mastite, uma inflamação das glândulas mamárias. A mastite é uma enfermidade que se caracteriza pelo aumento da CCS, podendo também aumentar as células bacterianas do leite. (LACERDA et al., 2010).

Em leites com elevada CBT, a fermentação da lactose por bactérias produz ácido lático, causando a acidez, a qual ainda é um dos problemas enfrentados pelos laticínios. A produção de enzimas extracelulares, como lipases e proteases de origem microbiana alteram o sabor e o odor, levando à perda de consistência na formação do coágulo para fabricação do queijo e à gelatinização do leite longa-vida (TAFFAREL et al., 2013).

Para a indústria, a presença de CCS elevada, é prejudicial pela queda no rendimento na produção de derivados além de alterações sensoriais do leite e a redução de vida de prateleira (DE ANDRADE et al., 2007). Segundo Callefe e Langoni (2015), a indústria de processamento de produtos lácteos tem sido mais exigente. No caso de desqualificação deve haver o descarte do leite.

Objetivou-se com este trabalho verificar a qualidade do leite cru fornecido para uma indústria de processamento de produtos lácteos de grande porte da região sul do Estado de Goiás comparando com os parâmetros estabelecidos na IN 62. Dentre as dez rotas de coleta de leite efetuadas pela indústria, foram analisados os leites de quatro produtores das duas principais rotas de abastecimento de coleta de leite referente ao conteúdo de gordura, proteína, lactose, EST, ESD, CCS, CBT e resíduo de antibiótico.

\section{MATERIAL E MÉTODOS}

No período de agosto a outubro de 2015 foram analisadas 55 amostras de leite cru de quatro produtores, sendo as quantidades de 09, 14, 20 e 12 amostras para os produtores $A, B, C e$ 
D, respectivamente de acordo com a quantidade de recepções da matéria-prima recebida no laticínio no período avaliado. As análises foram referentes ao conteúdo de gordura, proteína, lactose, EST, ESD, CCS, CBT e resíduo de antibiótico no leite cru. Dentre as dez rotas de coleta de leite efetuadas pela indústria, foram avaliados os leites fornecidos por produtores de duas principais rotas de abastecimento da indústria de processamento de produtos lácteos da região sul do Estado de Goiás, provenientes de ordenha manual (produtores B e D) e mecânica (produtores A e C).

O leite após a ordenha é armazenado em tanques de expansão com temperatura máxima de $4^{\circ} \mathrm{C}$ atendendo a IN 62 (BRASIL, 2011), sendo transportado no mesmo dia para a indústria, onde permaneceram por até dois dias até serem conduzidas para o Centro de Pesquisa em Alimentos (CPA). A quantidade de leite fornecida pelos quatro produtores mensalmente é de aproximadamente 75.000 litros de leite.

\subsection{Análises de antibióticos}

A análise de antibiótico betalactâmicos foi realizada no laboratório de controle de qualidade na indústria de processamento de produtos lácteos. Para os ensaios das 55 amostras avaliadas utilizaram-se os kits de detecção pelo método imunoenzimático e antimicrobiano da marca Charm.

O kit imunoenzimático utilizado foi o Beta Star, este identifica os resíduos de antibióticos penicilina G, ampicilina, amoxicilina, oxacilina, cloxacilinadicloxacilina, nafcilina, ceftiorfur, celfquinome, cefazolin, cephapirin, cefacetrile, cefoperazone e cefalonium misturados no leite cru, conforme informações do fornecedor.

Para casos positivos de antibiótico utilizou-se o kit do método antimicrobiano Charm para confirmação do resultado. De acordo com o fabricante, este kit detecta os resíduos de amoxicilina, ampicilina, cefacetrile, cefalexin, cefalonium, cefazolin, cefoperazone, cefquinome, ceftiofur, cephapirin, cloxacillin, dicloxacillin e penicillina G.

A interpretação dos resultados dos kits imunoenzimático e antimicrobiano baseou-se na coloração das linhas, onde o resultado negativo apresentava a linha teste " $T$ " mais escura ou da mesma cor que a linha controle " $C$ "; e o resultado positivo exibia a linha teste " $T$ " mais clara que a linha controle " $\mathrm{C}$ ".

\subsection{Análises físicas, químicas e microbiológicas}

As análises do leite para determinação do conteúdo de gordura, proteína, lactose, EST, ESD, CCS e CBT foram realizadas pelo Laboratório de Qualidade do Leite (LQL) no CPA da Escola de Veterinária e Zootecnia (EVZ) da Universidade Federal de Goiás (UFG). Para o transporte, as amostras do leite foram armazenadas em um frasco estéril, sendo que para as análises microbiológicas adicionou-se o bronopol, e para as análises físicas e químicas utilizou-se o azidiol, com temperatura máxima de 10 ㄷ $\mathrm{C}$ para conservação do leite até o momento da análise.

A análise de CCS foi realizada pelo método de citometria de fluxo em equipamento automatizado (Fossomatic 5000 Basic - FOSS e Somascope - Delta) de acordo com o ISO 13366 (IDF 148-2, 2006). A CBT foi realizada utilizando-se o equipamento Bactoscan FC (FOSS) e Bactocount IBC (Bentley) e cujo princípio analítico baseia-se na citometria de fluxo, conforme ISO 16297 (IDF 161, 2013).

A determinação dos resultados de gordura, EST e ESD foram realizadas no equipamento automatizado Milkoscan 4000 (Foss Electric) e proteína do leite, no Lactoscope (Delta) pelo método de infravermelho - Infra-red, descrito pela ISO 9622 (IDF 141C, 2013). 


\subsection{Análise estatística}

Os dados foram submetidos à análise de variância, sendo as médias dos resultados comparados pelo teste Tukey a $5 \%$ de probabilidade $(P<0,05)$, por meio do programa estatístico Assistat versão 7.7 beta (SILVA, 2014).

\section{RESULTADOS E DISCUSSÃO}

\subsection{Resultados das análises de antibióticos}

Os resíduos de betalactâmicos foram evidenciados em 4 amostras de leite cru, sendo o resultado positivo detectado apenas para um produtor, conforme Tabela 1.

Tabela 1. Resultados das análises de resíduos de antibióticos betalactâmicos nas amostras de leite cru coletadas dos produtores nos meses de agosto a outubro de 2015.

\begin{tabular}{ccccc} 
& & & \multicolumn{2}{c}{$\begin{array}{c}\text { Resíduos de antibióticos } \\
\text { Petalactâmicos }\end{array}$} \\
\cline { 3 - 5 } & Tipo de ordenha & Quantidade de amostras & Presente & Ausênte \\
\hline A & \multirow{2}{*}{ Mecânica } & 9 & 4 & 5 \\
C & \multirow{2}{*}{ Manual } & 20 & 0 & 20 \\
\hline B & 14 & 0 & 14 \\
D & & 12 & 0 & 12 \\
\hline Total & & 55 & 4 & 51 \\
\hline
\end{tabular}

Os resíduos de antibióticos foram detectados em 7,3\% das amostras. Portanto, pode-se observar que $75 \%$ dos produtores fazem a prática correta em relação ao período de carência dos medicamentos utilizados no combate a infecções como a mastite. De acordo com Nero et al. (2007), neste período os resíduos são eliminados no leite, sendo necessário o descarte da produção, pois essas substâncias não são eliminadas no beneficiamento.

A presença de antibióticos também foi detectada por Nero et al. (2007), onde foram avaliadas 210 amostras de leite cru obtidas por ordenha manual e mecânica de quatro importantes estados produtores de leite (MG, RS, PR e SP). Constatou a presença do resíduo antimicrobiano em $11,4 \%$ das amostras analisadas.

Mattos et al. (2010), ao pesquisar resíduos de antibióticos betalactâmicos em 53 amostras de leite cru no Estado de Pernambuco verificaram resultado positivo em 1,89\% das amostras analisadas. Comparando o número de amostras analisadas neste estudo com as amostras de Mattos et al. (2010), observa-se que a presença de resíduos de antibióticos foi maior no Estado de Goiás.

Vieira et al. (2012), obteve um percentual de resíduos de antibióticos em 19\% das 79 amostras avaliadas no leite pasteurizado do tipo B no estado do Paraná utilizando kits comerciais de ensaio imunoenzimático. Salas et al. (2013), constataram que $45 \%$ das amostras de leite de sessenta animais da bacia leiteira de Lima no Peru apresentavam resíduos de antibióticos betalactâmicos. Assim nota-se que os produtores fornecem leite cru com contaminação química, tornando essencial a avaliação de resíduos de antibióticos na indústria de processamento de produtos lácteos.

\subsection{Resultados das análises físicas, químicas e microbiológicas}

As médias estatísticas das análises físicas, químicas e microbiológicas do leite cru dos meses de agosto a outubro de 2015 estão apresentadas na Tabela 2. 
Tabela 2. Resultados das análises de qualidade do leite cru fornecido pelos produtores $A, B, C$ e $D$ nos meses de agosto a outubro de 2015.

\begin{tabular}{|c|c|c|c|c|}
\hline \multicolumn{5}{|c|}{ Tipo de ordenha } \\
\hline \multirow{2}{*}{ Parâmetros } & \multicolumn{2}{|c|}{ Mecânica } & \multicolumn{2}{|c|}{ Manual } \\
\hline & Produtor A & Produtor C & Produtor B & Produtor D \\
\hline Gordura (Mín. 3\%)* & $4,20^{a}$ & $3,44^{\mathrm{a}}$ & $3,38^{\mathrm{a}}$ & $3,36^{\mathrm{a}}$ \\
\hline Proteína (Mín. 2,9\%)* & $2,95^{a}$ & $3,25^{a}$ & $3,19^{a}$ & $3,30^{a}$ \\
\hline Lactose (Mín. 4,5\%)** & $4,26^{b}$ & $4,44^{\mathrm{ab}}$ & $4,61^{a}$ & $4,64^{a}$ \\
\hline EST $(\geq 11,40 \%)^{*}$ & $12,38^{\mathrm{a}}$ & $12,09^{a}$ & $12,17^{\mathrm{a}}$ & $12,28^{\mathrm{a}}$ \\
\hline $\operatorname{ESD}(\geq 8,40 \%)^{*}$ & $8,18^{b}$ & $8,64^{\mathrm{a}}$ & $8,79^{\mathrm{a}}$ & $8,92^{\mathrm{a}}$ \\
\hline CCS (Máx. $5 \times 10^{5} \mathrm{CS} / \mathrm{mL}$ ) * & $42,64^{\mathrm{a}}$ & $6,73^{b}$ & $1,84^{b}$ & $2,12^{b}$ \\
\hline CBT (Máx. $3 \times 10^{5} \mathrm{UFC} / \mathrm{mL}$ ) * & $13,26^{\mathrm{a}}$ & $0,26^{a}$ & $7,74^{a}$ & $0,69^{a}$ \\
\hline
\end{tabular}

Médias seguidas de letras diferentes na mesma linha representam diferença significativa pelo teste de

*Tukey a $5 \%(P \leq 0,05)$ de probabilidade.

*Padrões estabelecidos pela IN62

**Padrão estabelecido pelo Centro de Pesquisa em Alimentos (CPA).

Os valores encontrados para gordura, proteína e lactose fazem parte da composição de EST no leite. As médias do EST não diferiram significativamente $(P>0,05)$ entre os produtores $e$ atenderam a IN62 (BRASIL, 2011).

A média de ESD do leite do produtor $A$ diferiu significativamente $(P \leq 0,05)$ das amostras dos demais produtores. O produtor $A$, apresentou média de $8,18 \%$ de ESD, devido ao elevado conteúdo de gordura do leite e teor de lactose reduzido. 0 teor médio de ESD do produtor A foi menor do que o apresentado pelo leite dos demais produtores, além de não atender aos limites estabelecidos pela legislação. Condição semelhante foi verificada por Montanhini e Hein (2013), ao avaliarem 23 amostras de leite cru no Estado do Paraná constataram que 48\% destas estavam com ESD em desacordo com a legislação.

Tabela 3.Média Geométrica das análises de CCS e CBT do leite cru fornecido pelos produtores A, B, C e D no período de agosto a outubro de 2015.

\begin{tabular}{ccc}
\hline \multicolumn{3}{c}{ Média Geométrica } \\
\hline \multirow{2}{*}{ Produtor } & CCS & CBT \\
& Máx. $5 \times 10^{5} \mathrm{CS} / \mathrm{mL}^{* *}$ & Máx. $\mathbf{3} \times 10^{5} \mathrm{UFC} / \mathrm{mL}^{* *}$ \\
\hline A & $37,42^{*}$ & 2,71 \\
B & 1,82 & 1,41 \\
C & $6,69^{*}$ & 0,25 \\
D & 1,52 & 0,44 \\
\hline
\end{tabular}

*Médias Geométricas que não atendem a IN62 (BRASIL, 2011)

** Limite estabelecido pela IN62 (BRASIL, 2011)

A média estatística de CCS do produtor $A$ diferiu significativamente $(P \leq 0,05)$ dos demais produtores. Segundo Motta et al. (2015), a alta celularidade no leite é ocasionada, principalmente, por deficiências no manejo higiênico da ordenha que resultam na ocorrência de mastite e, secundariamente, relacionada a outros fatores como: à fase da lactação, idade e raça do animal. Da Silva et al. (2013) também alcançaram valores de CCS no leite ordenhado mecanicamente superior ao leite obtido através de ordenha manual. 
Para melhor avaliação da qualidade do leite a IN 62 (BRASIL, 2011), estabelece a realização da média geométrica sobre um período de 03 (três) meses, com pelo menos 01 (uma) análise mensal para os resultados de CCS e CBT, conforme Tabela 3.

Todos os produtores obtiveram média geométrica de CBT dentro dos limites estabelecidos pela legislação. De acordo com Salomão (2012), valores de CBT superiores ao padrão determinado pela IN 62 (BRASIL, 2011) sugerem contaminação devido a fatores, como o uso inadequado ou a não utilização de produtos de limpeza e sanitização nos equipamentos de ordenha e/ou no tanque de refrigeração, falhas na realização do predipping (desinfecção dos tetos pré-ordenha), tetos e úberes contaminados por microrganismos, qualidade da água utilizada na limpeza dos tetos e dos equipamentos de ordenha, ineficiente refrigeração do leite até o momento da coleta pelas indústrias de beneficiamento e mastite.

As médias geométricas de CCS do leite ordenhado mecanicamente dos produtores A e C apresentaram-se acima dos limites estabelecidos pela IN62 (BRASIL, 2011). A elevada CCS para o produtor A foi indicativa de uma infecção. Esta infecção foi confirmada com a detecção de resíduos de antibiótico em algumas amostras analisadas no mesmo período.

De acordo com Rodrigues (2009), além da infecção, a CCS pode-se elevar em vacas no final da lactação, principalmente em estágio de gestação avançada; em vacas com idade avançada; stress; injúrias do tecido mamário; e ordenha conduzida de forma inadequada, principalmente, a mecânica quando não se regula corretamente o vácuo ou não se retira as teteiras após o esgotamento completo da vaca. Essas causas podem justificar a alteração na média geométrica de CCS para o produtor $C$, pois não foi detectada a presença de resíduos de betalactâmico e a média geométrica de CBT da tabela 3 apresentou-se no limite determinado pela IN 62 (BRASIL, 2011).

Segundo Silva (2011), altas CCS ocasionam diversas mudanças na composição do leite, afetando sua qualidade, pois alteram a permeabilidade dos vasos sanguíneos da glândula e reduzem a secreção dos componentes do leite sintetizados na glândula mamária (proteína, gordura e lactose) pela ação direta dos patógenos ou de enzimas sobre os componentes secretados no interior da glândula.

De acordo com Busnello (2008), a caseína e a gordura são responsáveis pela consistência e cor dos produtos lácteos, elas têm importância fundamental na manufatura de derivados do leite representando a maior concentração dos sólidos, sendo essa concentração de elementos sólidos que determinam o valor industrial do leite, pois quanto mais gordura e proteína, maior o rendimento que a indústria terá ao fabricar os derivados lácteos.

Os resultados de resíduos de antibióticos, ESD e CCS encontrados que não atenderam aos limites estabelecidos pela IN 62 (BRASIL, 2011) demonstram baixa qualidade do leite. De Vargas et al. (2014), ao avaliar a CCS e parâmetros físicos, químicos e microbiológicos do leite informaram que os danos causados a indústria de derivados lácteos são: a coagulação e floculação do leite; mudanças significativas na viscosidade e sabor do iogurte; alterações na fabricação de queijos, como a redução no rendimento industrial; alterações negativas nas propriedades sensoriais; defeitos de textura e elevada perda de sólidos no soro do queijo.

\section{CONCLUSÕES}

A presença de betalactâmicos verificada neste estudo demonstra a importância da avaliação deste parâmetro na indústria, uma vez que a contaminação química por antibióticos não é possível ser eliminada do leite e representa riscos à saúde pública e prejuízos para a indústria de processamento de produtos lácteos.

Os resultados de CCS e CBT demonstram que não há uma relação necessariamente direta entre estes parâmetros, conforme médias estatísticas apresentadas para os produtores A e C. 
A alta CCS decorrente de valores elevados de CBT indicam favorecer redução no teor de lactose e alterações químicas no leite que prejudicam a qualidade do mesmo e consequentemente dos derivados lácteos.

\section{REFERÊNCIAS}

ALMEIDA, T. V. Parâmetros de qualidade do leite cru bovino: contagem bacteriana total e contagem de células somáticas. 2013. Seminário (Mestrado em Ciência Animal) - Universidade Federal de Goiás, Goiania, 2013.

ARAUJO, G. B.; SANTOS H. de A.; FARIAS, C. E.; VIANA, D. de A. F.; VIEIRA, E. S.; JÚNIOR, A. M. F. Deteç̧ão de resíduo de antibiótico em leite in natura em laticínio sob inspeção federal. Scientia Plena, Aracaju, v. 11, n. 4, p. 1-6, 2015.

BRASIL. Instrução Normativa $\mathrm{n}^{\circ} 51$, de 18 de setembro de 2002. Aprovar os Regulamentos Técnicos de Produção, Identidade e Qualidade do Leite tipo A, do Leite tipo B, do Leite tipo C, do Leite Pasteurizado e do Leite Cru Refrigerado e o Regulamento Técnico da Coleta de Leite Cru Refrigerado e seu Transporte a Granel. Diário Oficial da União, Poder executivo, Brasília, DF, 21 set. 2002. Seção 1, p.13.

BRASIL. Instrução Normativa no 62, de 29 de dezembro de 2011. Aprova o Regulamento Técnico de Produção, Identidade e Qualidade do Leite tipo A, o Regulamento Técnico de Identidade e Qualidade de Leite Cru Refrigerado, o Regulamento Técnico de Identidade e Qualidade de Leite Pasteurizado e o Regulamento Técnico da Coleta de Leite Cru Refrigerado e seu Transporte a Granel. Diário Oficial da República Federativa do Brasil, Poder executivo, Brasília, DF, 30 dez. 2011. Seção 1, p. 1-24.

BUSNELLO, S. R. Aspectos da Qualidade do Leite e Produção de Queijo Minas Frescal. 2008. $39 \mathrm{f}$. Trabalho de Conclusão de Curso (Medicina Veterinária) - Centro das Faculdades Metropolitanas Unidas - FMU, São Paulo, 2008.

CALLEFE, J. L. R.; LANGONI, H. Qualidade do leite: uma meta a ser atingida. Revista Veterinária e Zootecnia, Botucatu, v. 22, n. 2, p. 151-162, 2015.

DA SILVA, M. A. P.; BRASIL, R. B.; CABRAL, J. F.; GARCIA, J. C.; DE OLIVEIRA, A. N. Qualidade do leite cru refrigerado obtido através de ordenha manual e mecânica / Qualityofrefrigeratedrawmilkobtainedbymilkingmachineand manual. Revista do Instituto de Laticínios Cândido Tostes, Juiz de Fora, v. 68, n. 390, p. 5-11, 2013.

DE ANDRADE, L. M.; El Faro, L.; CARDOSO, V. L. Efeitos genéticos e de ambiente sobre a produção de leite e a contagem de células somáticas em vacas holandesas. Revista Brasileira de Zootecnia, Jaboticabal, v.36, p.343-349, 2007.

DE VARGAS, D. P.; NÖRNBERG, J. L.; DE OLIVEIRA M. R.; SHEIBLER, R. B.; BREDA, F. C.; MILANI, M. P. Correlações entre contagem de células somáticas e parâmetros físico-químicos e microbiológicos de qualidade do leite. Ciência animal. Goiânia, vol.15, n.4, pp. 473-483, 2014.

INTERNATIONAL DAIRY FEDERATION.ISO 13366-2 / IDF 148-2 - Milk - Enumeration of somatic cells - Part. 2: Guidance on the operation of fluoro-opto-electronic counters. Bruxelas, Bélgica: ISO, 2006. $15 p$. 
INTERNATIONAL DAIRY FEDERATION.ISO 16297 / IDF 161 - Milk Bacterial count - Protocol for the evalution of alternative methods: Bruxelas, Bélgica: ISO, 2013. 13 p.

INTERNATIONAL DAIRY FEDERATION.ISO 9622 / IDF 141C - Determination of milkfat, protein and lactose content - Guidance on the operation of mid-infrared instruments.Bruxelas, Bélgica: ISO, 2013.15p.

LACERDA, L. M.; MOTA, R. A.; SENA, M. J. Contagem de células somáticas, composição e contagem bacteriana total do leite de propriedades leiteiras nos municípios de Miranda do Norte, ItapecurúMirim e Santa Rita, no Estado do Maranhão. Arquivo do Instituto Biológico, São Paulo, v.77, n.2, p.209-215, 2010.

MATTOS, M. R.; BELOTI, V.; TAMANINI, R.; MAGNANI, D. F.; NERO, L. A.; BARROS, M. DE A. F.; PIRES, E. M. F.; PAQUEREAU, B. P. D. Qualidade do leite cru produzido na região do agreste de Pernambuco. Semina: Ciências Agrárias, Londrina, v. 31, n. 1, p. 173-182, 2010. https://doi.org/10.5433/1679-0359.2010v31n1p173

MONTANHINI, M. T. M.; HEIN, K. K. Qualidade do leite cru comercializado informalmente no município de Piraí do Sul, Estado do Paraná, Brasil. Revista do Instituto de Laticínios Cândido Tostes, Juiz de Fora, v. 68, n. 393, p. 10-14, 2013. https://doi.org/10.5935/2238-6416.20130030

MOTTA, R. G.; SILVA, A. V.; GIUFFRIDA, R.; SIQUEIRA, A. K.; PAES, A. C.; MOTTA, I. G.; LISTONI, F. J. P.; RIBEIRO, M. G. Indicadores de qualidade e composição de leite informal comercializado na região Sudeste do Estado de São Paulo. Pesquisa Veterinária Brasileira. São Paulo, v. 35, n. 5, p. 417-423, mai. 2015.

NERO, L. A.; MATTOS, M. D.; BELOTI, V.; BARROS, M. A. F.; FRANCO, B. D. G. M. Resíduos de antibióticos em leite cru de quatro regiões leiteiras no Brasil. Ciência e Tecnologia de Alimentos. Campinas, v. 27, n. 2, p. 391-393, abr.-jun. 2007.

RODRIGUES, M. G. R. Mastite bovina e suas consequências na qualidade do leite. 2009. $48 f$. Trabalho de Conclusão de Curso (Especialização lato sensu em Defesa e Vigilância Sanitária Animal) - Universidade Castelo Branco, Vitória, 2009.

SALAS, Z.; CALLE, E.; FALCÓN, T.; PINTO, J.; ESPINOZA, B. Determinación de residuos de antibióticos betalactámicos mediante unensayoinmunoenzimáticoenleche de vacas tratadas contra mastitis. Revista de InvestigacionesVeterinariasdelPerú, vol.24, n.2, p. 252-254, 2013. https://doi.org/10.15381/rivep.v24i2.2519

SALOMÃO, V. S. C. Influência de diferentes tipos de micro-organismos na contagem bacteriana total e de células somáticas por citometria de fluxo e na composição centesimal do leite cru. 2012. 49f. Dissertação (Mestrado em Ciência Animal) - Universidade Federal de Minas Gerais, Belo Horizonte, 2012.

SILVA, A. M. Estudo da composição química, contagem de células somáticas e contagem bacteriana total do leite cru inspecionado pelo serviço estadual nos estados de Pernambuco, Paraíba e Rio Grande do Norte. 2011. 68f. Dissertação (Mestrado em Zootecnia) - Universidade Federal Rural do Pernambuco, Recife, 2011. 
SILVA, D. P. da; GELLEN, L. F. A; SILVA, T. S.; COSTA, J. da L.; SILVA, A. L. L.; SCHEIDT, G. N. Resíduos de antibiótico em leite: prevalência, danos à saúde e prejuízos na indústria de laticínios. 2013. 16f. Trabalho acadêmico - Tecnologia de Alimentos, Universidade do Estado do Pará, 2013.

SILVA, F. A. S. ASSISTAT-Assistência Estatística-versão 7.7 beta (pt). Programa computacional. Universidade Federal de Campina Grande Campus de Campina Grande-PB-DEAG/CTRN, 2014. SILVA, T. dos S. Plano nacional de controle de resíduos e contaminantes em leite (antibióticos). 2009. 26 f. Trabalho de Pós-Graduação em Ciência Animal da Escola de Veterinária - Universidade Federal de Goiás, Goiânia, 2009.

SILVA, T. T. Mastite bovina e sua relação com a produção e composição do leite. 2014. $38 f$. Trabalho de Conclusão de Curso (Zootecnia) - Universidade Federal de Goiás, Goiânia, 2014.

TAFFAREL, L. E.; COSTA, P. B.; DE OLIVEIRA, N. T. E.; BRAGA, G. C.; ZONIN, W. J. Contagem bacteriana total do leite em diferentes Sistemas de ordenha e de resfriamento. Arquivos do Instituto Biológico. São Paulo, v. 80, n. 1, p. 7-11, jan./mar.,2013.

VIEIRA, T. S. W. J.; RIBEIRO, M. R.; NUNES, M. P.; JÚNIOR, M. M.; NETTO, D. P. Detecção de resíduos de antibióticos em amostras de leite pasteurizado do Estado do Paraná, Brasil. Semina: Ciências Agrárias. Londrina, v. 33, n. 2, p. 791-796, abr. 2012. 